\title{
INFLUENCE OF SECONDARY PHASE PRECIPITATION ON RESISTANCE TO INTERGRANULAR CORROSION OF AISI 316L AUSTENITIC STAINLESS STEEL
}

The AISI 316L steel after cold working of $40 \%$ and subsequent annealing at $750^{\circ} \mathrm{C}$ for 1, 2, 5, 10, 50, or $100 \mathrm{~h}$ was investigated. For the microstructure characterization the light microscopy and the transmission electron microscopy were used. To determine the sensitivity to intergranular corrosion the test was performed according to ASTM A 262, practice A. The transition between non-sensitised and sensitised states was found to be between 1 and $2 \mathrm{~h}$ of annealing. Sigma, laves and chi phases were identified in all the analyzed conditions. $M_{23} C_{6}$ was found to start to precipitate between 5 and $10 \mathrm{~h}$ of annealing. Sigma, chi, and $M_{23} C_{6}$ precipitated mainly along the grain boundaries. Laves precipitated mainly inside the grains, and after $50 \mathrm{~h}$ of annealing also intergranularly. Time dependent changes in the average metal composition of particular phases were considered as negligible.

Key words: austenitic stainless steel, intergranular corrosion, secondary phase precipitation, transmission electron microscopy

\section{Introduction}

Austenitic stainless steels (ASS) are frequently used as construction materials of various components in chemical, petrochemical, pharmaceutical and nuclear power industries, because of their excellent corrosion resistance and good mechanical properties at elevated temperatures [1-4]. However, properties of these steels depend strongly on structural, compositional, and morphological characteristics of the grain boundaries, e.g. on the state of intergranular precipitation [5-7].

On heat treatment, welding or service, the unstabilized ASS can be sensitised if isothermally exposed at temperatures 500$800^{\circ} \mathrm{C}$ or slowly cooled through this temperature range $[1,4,8,9]$. The sensitisation resulting from microstructural changes can cause intergranular corrosion of unstabilized ASS. The microstructural changes evoking the sensitisation reside mostly in the precipitation of secondary chromium-rich phases (e.g. $\mathrm{M}_{23} \mathrm{C}_{6}$, sigma, chi) along the grain boundaries followed by the formation of chromiumdepleted zones with chromium content below $12 \mathrm{wt} \%$ [10].

Sigma, as a typical phase occurring in the $316 \mathrm{~L}$ steel, precipitates at temperatures between $550-900^{\circ} \mathrm{C}$ on grain boundaries, especially on triple points, incoherent twin boundaries and intergranular inclusions [11]. The sigma precipitation has a very slow kinetics, so the formation of precipitates can take hundreds to thousands of hours. Cold work $(\mathrm{CW})$ accelerates its precipitation particularly if also recrystallization occurs on subsequent annealing [11]. Chi is mostly a minor phase and it was found in the
AISI 316L steel at temperatures about $750{ }^{\circ} \mathrm{C}$ [7]. The formation of this phase can be observed mainly on the grain boundaries, incoherent twin boundaries, coherent twin boundaries and on dislocations within the matrix. Owing to its ability to dissolve carbon and also to its easier nucleation, the chi precipitation, when it occurs, precedes the sigma formation. The chi nucleation is also accelerated by cold work [11]. Laves of the $\mathrm{Fe}_{2} \mathrm{Mo}$ type was found in AISI 316 steels with the bulk Mo content between 2-3 wt.\% after long-term annealing. It is often a minor phase precipitating intragranularly in the form of equiaxed particles, with occasional occurrence at the grain boundaries [11].

The degree of sensitisation is influenced by many factors, e.g. bulk composition of the steel, grain size, plastic deformation, timetemperature exposure $[1,2,4,7]$. The influence of time-temperature exposure on the steel sensitisation can be derived from timetemperature-sensitisation (TTS) diagram. In the diagram, each condition characterized by time and temperature of annealing is assigned to the sensitised or the non-sensitised areas separated by typical C-curve. The nose of this curve defines the critical temperature with the minimal time for sensitisation.

In the present work the AISI $316 \mathrm{~L}$ steel was investigated. The aim of the study resides in the determination of relationships between the steel thermal-deformation history, its resistance to intergranular corrosion, and the state of precipitation. The attention was paid to the characterization of type, metal composition, amount, and distribution of secondary phase particles.

\footnotetext{
* K. Bartova ${ }^{1}$, M. Domankova ${ }^{2}$, J. Janovec ${ }^{3}$

${ }^{1}$ Institute of Materials Science, Faculty of Materials Science and Technology in Trnava,

${ }^{2}$ Slovak University of Technology in Bratislava, Slovakia, E-mail.: katarina.bartova@stuba.sk
} 


\section{Experimental procedure}

The chemical composition of the investigated AISI $316 \mathrm{~L}$ steel is given in Table 1. In the first step, the steel was solution annealed for $1 \mathrm{~h}$ at $1100{ }^{\circ} \mathrm{C}$. Immediately after the solution annealing, the steel was water quenched to eliminate the formation of new precipitates. In the second step, cold working of the steel sheets was applied at ambient temperature with the deformation of $40 \%$ toward the original sheet thickness. The final step of the sample treatment resided in the isothermal annealing performed at $750{ }^{\circ} \mathrm{C}$ for $1,2,5,10,50$ and $100 \mathrm{~h}$.

The samples for the light microscopy were polished up to fine diamond finish $(\sim 1 \mu \mathrm{m})$ and then electrolytically etched for 10 $30 \mathrm{~s}$ (in dependence on the sample sensitisation) using $10 \%$ oxalic acid at the current density 1 A.cm ${ }^{-2 .}$ The metallographic sections were observed by a light microscope NEOPHOT 32 equipped with CCD camera. The samples were tested to determine the sensitivity to intergranular corrosion according to ASTM A 262, practice A (Oxalic Acid Etch Test). In the corrosion test, the same etching procedure as described above for preparing metallographic samples was used, except for the etching time taking $90 \mathrm{~s}$. The following criterion was applied to classify the sensitivity of the etched microstructures to the intergranular corrosion:

- the step structure, when the grain boundaries are not attacked by corrosion,

- the dual structure, when the grains are not completely surrounded by deeply etched boundaries,

- the ditch structure, when at least one grain is completely surrounded by deeply etched boundaries.

The samples showing step or dual structures were considered to be non-sensitised, whereas the samples exhibiting the ditch structure were classified as sensitised [12].

For the identification of secondary phases the transmission electron microscopy (TEM) of extraction carbon replicas was utilised. TEM observations were performed using a JEOL 200 CX microscope operated at $200 \mathrm{kV}$. It was equipped with an energy dispersive

X-ray spectrometer (EDX). The samples for TEM were prepared as follows:

- etching of the mechanically polished surfaces for 2-3 min with etchant consisting of $10 \mathrm{ml} \mathrm{H}_{2} \mathrm{SO}_{4}, 10 \mathrm{ml} \mathrm{HNO}{ }_{3}, 20 \mathrm{ml} \mathrm{HF}$ and $50 \mathrm{ml} \mathrm{H}_{2} \mathrm{O}$,

- coating of the surfaces with a thin layer of carbon,

- removing the carbon film from the samples in $8 \%$ solution of $\mathrm{HCl}$ in ethanol.
At least ten EDX analyses per secondary phase were performed for each condition. At the evaluation of EDX spectra the standardless method for thin specimens was used.

The phase equilibria were calculated for the system corresponding to the investigated steel in the temperature range $500-1500{ }^{\circ} \mathrm{C}$ by ThermoCalc software [13] using the database STEEL17 formulated by Kroupa et al. [14]. In the calculation procedure the total Gibbs energy of the system consisting of contributions of individual phases is minimized at constant temperature and pressure. The particular phases were modelled as a sum of the reference level of Gibbs energy, entropy term, excess Gibbs energy, and magnetic term (if plausible the magnetic ordering). In the calculations, the elements $\mathrm{Fe}, \mathrm{C}, \mathrm{Si}, \mathrm{Mn}, \mathrm{Cr}$, Mo and Ni were considered, and the phases liquid, delta-ferrite (b.c.c.), austenite (f.c.c.), laves (h.c.p.), $\mathrm{M}_{6} \mathrm{C}$ (f.c.c.), $\mathrm{M}_{23} \mathrm{C}_{6}$ (f.c.c.), sigma (tetragonal) and chi (b.c.c.) were taken into account.

\section{Results}

The microstructures of the investigated steels after the solution annealing are composed of polyhedral austenitic grains containing twins (Fig. 1a). After cold working the grains are prevailingly acicular and contain shear bands (Fig. 1b). No precipitates were observed at the grain boundaries of both solution annealed and cold worked conditions. Black discrete areas randomly distributed across the microstructure of the cold worked condition are probably etching artefacts.

TTS diagram for the AISI $316 \mathrm{~L}$ steel after $40 \%$ cold working is illustrated in Fig. 2a. Circles represent experimental results after oxalic acid etch test for the conditions annealed at $750{ }^{\circ} \mathrm{C}$. The solid circles represent sensitised conditions showing the ditch structure. The condition $750^{\circ} \mathrm{C} / 1 \mathrm{~h}$ exhibiting the dual structure is illustrated by the empty circle. The microstructures corresponding to conditions $750{ }^{\circ} \mathrm{C} / 1 \mathrm{~h}$ and $750{ }^{\circ} \mathrm{C} / 5 \mathrm{~h}$ are documented in Figs. $2 b$ and $2 c$, respectively.

On annealing, secondary phases were observed to start to precipitate on the grain boundaries and in the grain interior. The phases identified are summarized in Table 2. Figs. 3a and $3 \mathrm{~b}$ show the microstructures of the investigated steel after annealing at $750{ }^{\circ} \mathrm{C}$ for $1 \mathrm{~h}$ and $2 \mathrm{~h}$, respectively. $\mathrm{M}_{23} \mathrm{C}_{6}$ (Fig. 4), chi (Fig. 5) and sigma (Fig. 6) were identified on grain boundaries. Moreover, the particles of laves (Fig. 7) were evidenced. In Figs. 4-7 both the analysed particles and the corresponding diffraction patterns are documented. Average metal compositions of identified secondary phases in the analysed conditions can be seen in Table 3 .

\begin{tabular}{|c|c|c|c|c|c|c|c|c|c|c|c|}
\hline \multirow{2}{*}{ Steel } & \multicolumn{10}{|c|}{ Contents of elements in wt.\% } \\
\cline { 2 - 21 } & $\mathrm{C}$ & $\mathrm{N}$ & $\mathrm{Si}$ & $\mathrm{Mn}$ & $\mathrm{P}$ & $\mathrm{S}$ & $\mathrm{Cr}$ & $\mathrm{Ni}$ & $\mathrm{Mo}$ & $\mathrm{Ti}$ & $\mathrm{Fe}$ \\
\hline AISI 316L & 0.021 & 0.019 & 0.62 & 1.10 & 0.0027 & 0.004 & 17.47 & 12.20 & 2.10 & - & bal. \\
\hline
\end{tabular}



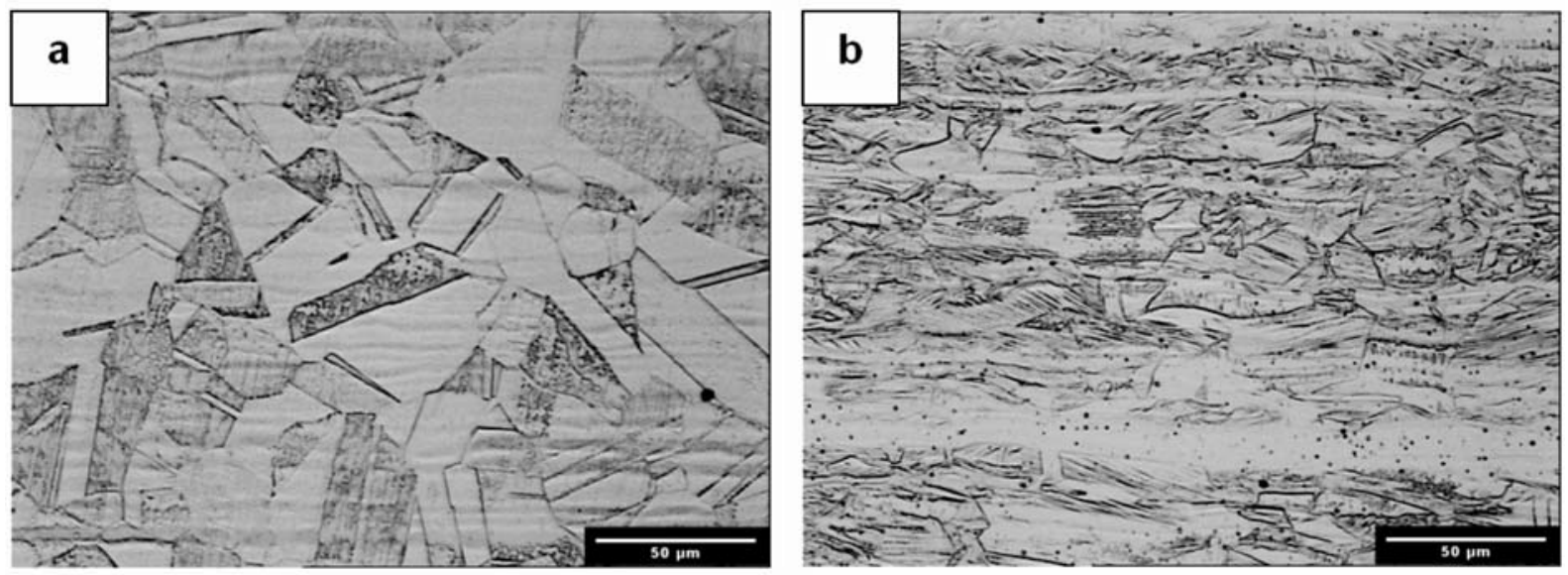

Fig. 1 Microstructures of the investigated steel after solution annealing (a) and subsequent $40 \%$ cold work (b)

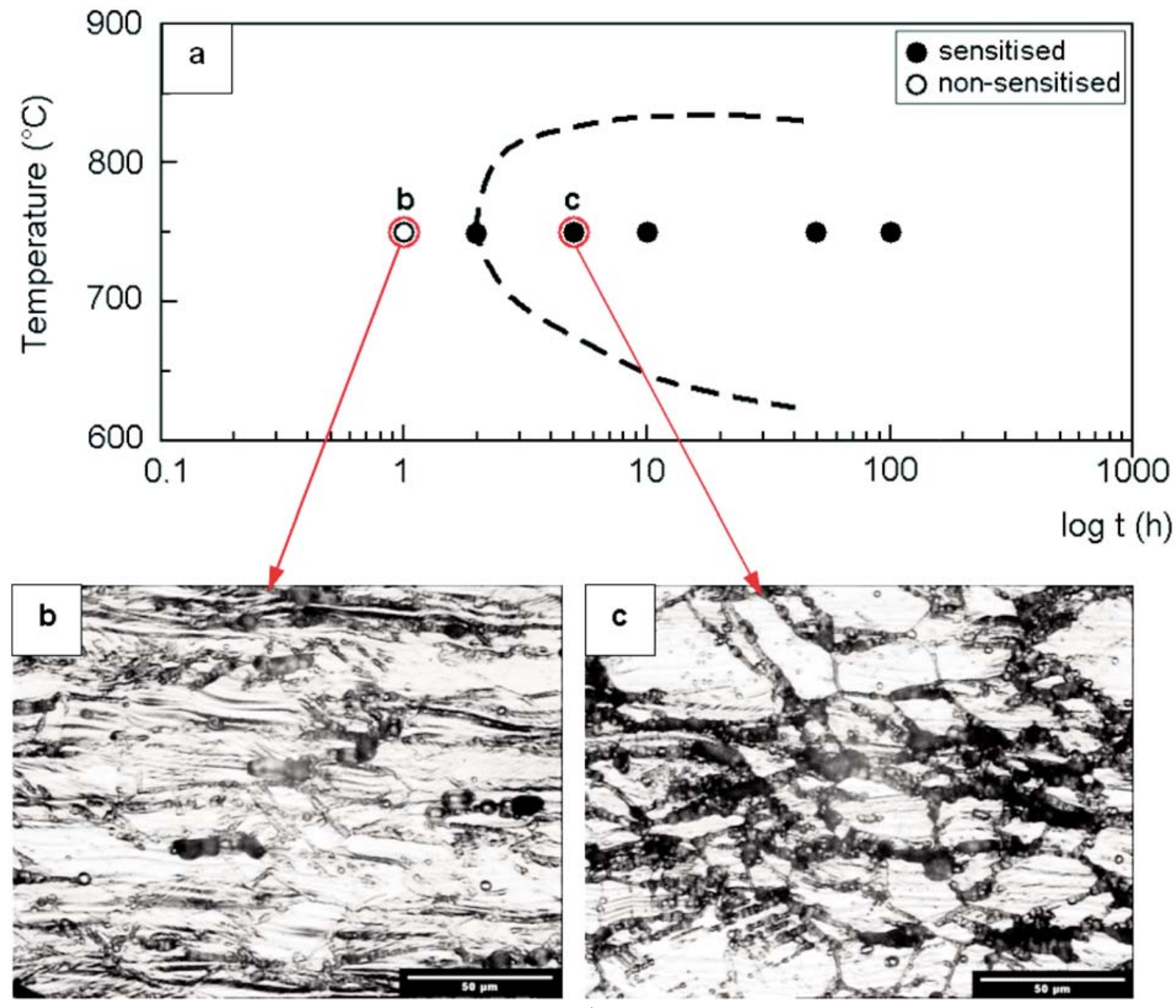

Fig. 2 TTS diagram for the AISI 316L steel after 40\% cold working ( the circles represent experimental results after oxalic acid etch test for conditions annealed at $\left.750{ }^{\circ} \mathrm{C}\right)\left(\right.$ a), the microstructure of condition $750{ }^{\circ} \mathrm{C} / 1 \mathrm{~h}$ - dual structure $(b)$,

the microstructure of condition $7500^{\circ} \mathrm{C} / 5 \mathrm{~h}$ - ditch structure (c) 
Experimentally identified secondary phases in the investigated steel after $40 \%$ cold working and

Table 2

subsequent annealing at $750^{\circ} \mathrm{C}$. Occurrence of a phase is denoted with symbol " $\mathrm{X}$ "

\begin{tabular}{|c|c|c|c|c|}
\hline \multirow{2}{*}{ Annealing time (h) } & \multicolumn{4}{|c|}{ Secondary phases } \\
\cline { 2 - 5 } & Sigma & Laves & Chi & $\mathrm{M}_{23} \mathrm{C}_{6}$ \\
\hline 2 & $\mathrm{X}$ & $\mathrm{X}$ & $\mathrm{X}$ & - \\
\hline 5 & $\mathrm{X}$ & $\mathrm{X}$ & $\mathrm{X}$ & $\mathrm{X}$ \\
\hline 10 & $\mathrm{X}$ & $\mathrm{X}$ & $\mathrm{X}$ & $\mathrm{X}$ \\
\hline 50 & $\mathrm{X}$ & $\mathrm{X}$ & $\mathrm{X}$ & $\mathrm{X}$ \\
\hline 100 & $\mathrm{X}$ & $\mathrm{X}$ & $\mathrm{X}$ & \\
\hline
\end{tabular}
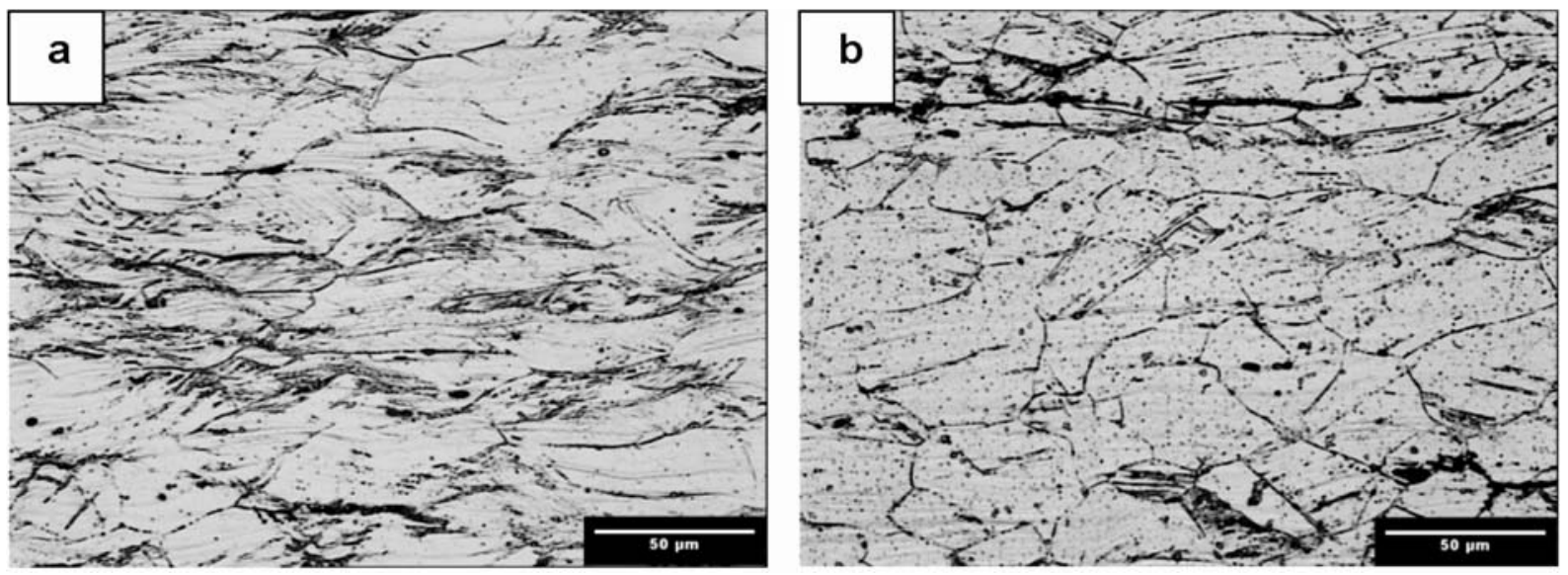

Fig. 3 Microstructures of the investigated steel after annealing at $750{ }^{\circ} \mathrm{C} / 1 \mathrm{~h}(\mathrm{a}), 750{ }^{\circ} \mathrm{C} / 2 \mathrm{~h}(\mathrm{~b})$

Metal compositions of identified secondary phases in conditions annealed at $750{ }^{\circ} \mathrm{C}$.

Table 3

Average metal compositions of particular phases regardless of condition are highlighted (italic + bolt)

\begin{tabular}{|c|c|c|c|c|c|c|}
\hline \multirow{2}{*}{ Secondary phases } & \multirow{2}{*}{ Annealing time $(\mathrm{h})$} & \multicolumn{5}{|c|}{ Mass contents of elements in $\%$} \\
\hline & & $\mathrm{Cr}$ & $\mathrm{Fe}$ & Mo & $\mathrm{Ni}$ & $\mathrm{Si}$ \\
\hline \multirow{5}{*}{ Sigma } & 2 & $33.0 \pm 1.3$ & $51.2 \pm 2.6$ & $10.6 \pm 2.6$ & $4.0 \pm 0.6$ & $1.3 \pm 0.4$ \\
\hline & 5 & $32.9 \pm 3.9$ & $46.4 \pm 4.8$ & $12.9 \pm 3.2$ & $5.7 \pm 2.7$ & $2.0 \pm 2.0$ \\
\hline & 10 & $32.7 \pm 3.2$ & $48.0 \pm 4.8$ & $11.9 \pm 4.4$ & $5.1 \pm 2.5$ & $2.3 \pm 2.7$ \\
\hline & 50 & $31.9 \pm 2.5$ & $47.8 \pm 1.1$ & $13.5 \pm 2.7$ & $5.0 \pm 0.6$ & $1.9 \pm 0.6$ \\
\hline & 100 & $32.7 \pm 2.2$ & $49.4 \pm 2.8$ & $11.3 \pm 3.0$ & $5.2 \pm 1.2$ & $1.5 \pm 0.9$ \\
\hline \multicolumn{2}{|c|}{ Average metal composition of sigma } & $32.6 \pm 0.9$ & $48.6 \pm 3.6$ & $12.0 \pm 2.3$ & $5.0 \pm 1.2$ & $1.8 \pm 0.8$ \\
\hline \multirow{5}{*}{ Laves } & 2 & $14.4 \pm 4.2$ & $28.6 \pm 6.5$ & $49.0 \pm 8.3$ & $3.8 \pm 2.1$ & $4.2 \pm 4.0$ \\
\hline & 5 & $12.4 \pm 5.5$ & $24.7 \pm 6.6$ & $51.5 \pm 7.0$ & $5.8 \pm 4.1$ & $5.6 \pm 5.5$ \\
\hline & 10 & $11.7 \pm 3.6$ & $27.1 \pm 9.0$ & $49.6 \pm 9.5$ & $4.8 \pm 4.6$ & $6.7 \pm 5.7$ \\
\hline & 50 & $9.7 \pm 1.4$ & $25.9 \pm 2.5$ & $51.0 \pm 2.9$ & $5.0 \pm 1.1$ & $8.4 \pm 4.4$ \\
\hline & 100 & $10.1 \pm 1.7$ & $29.5 \pm 1.3$ & $49.5 \pm 2.0$ & $5.1 \pm 1.5$ & $5.9 \pm 2.7$ \\
\hline \multicolumn{2}{|c|}{ Average metal composition of laves } & $11.7 \pm 3.5$ & $27.2 \pm 3.3$ & $50.1 \pm 2.1$ & $4.9 \pm 1.4$ & $6.2 \pm 3.1$ \\
\hline \multirow{5}{*}{ Chi } & 2 & $21.5 \pm 4.3$ & $39.1 \pm 4.0$ & $33.2 \pm 7.3$ & $3.4 \pm 1.9$ & $2.7 \pm 1.2$ \\
\hline & 5 & $25.6 \pm 1.0$ & $44.3 \pm 2.9$ & $23.7 \pm 3.0$ & $4.1 \pm 1.2$ & $2.5 \pm 0.2$ \\
\hline & 10 & $24.3 \pm 4.4$ & $43.4 \pm 5.7$ & $26.0 \pm 5.6$ & $4.1 \pm 1.6$ & $2.2 \pm 1.8$ \\
\hline & 50 & $23.3 \pm 1.8$ & $41.6 \pm 2.3$ & $27.0 \pm 2.5$ & $4.6 \pm 0.7$ & $3.5 \pm 1.4$ \\
\hline & 100 & $22.4 \pm 3.3$ & $45.1 \pm 5.0$ & $25.2 \pm 5.8$ & $4.7 \pm 0.9$ & $2.5 \pm 2.2$ \\
\hline \multicolumn{2}{|c|}{ Average metal composition of chi } & $23.4 \pm 3.1$ & $42.7 \pm 4.3$ & $27.0 \pm 7.1$ & $4.2 \pm 0.9$ & $2.7 \pm 1.0$ \\
\hline
\end{tabular}


COMMNICOIIONS

\begin{tabular}{|c|c|c|c|c|c|c|}
\hline \multirow{2}{*}{ Secondary phases } & \multirow{2}{*}{ Annealing time $(\mathrm{h})$} & \multicolumn{5}{|c|}{ Mass contents of elements in \% } \\
\cline { 2 - 7 } & & $\mathrm{Cr}$ & $\mathrm{Fe}$ & $\mathrm{Mo}$ & $\mathrm{Ni}$ & $\mathrm{Si}$ \\
\hline \multirow{3}{*}{$\mathrm{M}_{23} \mathrm{C}_{6}$} & 10 & $65.9 \pm 0.9$ & $15.0 \pm 0.2$ & $16.0 \pm 0.9$ & $2.9 \pm 0.2$ & $0.3 \pm 0.0$ \\
\cline { 2 - 7 } & 50 & $66.6 \pm 5.5$ & $13.7 \pm 2.6$ & $16.0 \pm 4.5$ & $3.2 \pm 1.1$ & $0.6 \pm 1.0$ \\
\cline { 2 - 7 } & 100 & $68.6 \pm 2.3$ & $13.6 \pm 0.4$ & $13.7 \pm 2.0$ & $3.5 \pm 0.4$ & $0.7 \pm 0.3$ \\
\hline \multicolumn{2}{|l}{ Average metal composition of $\mathrm{M}_{23} \mathrm{C}_{6}$} & $67.0 \pm 1.5$ & $14.1 \pm 1.0$ & $15.2 \pm 1.4$ & $3.2 \pm 0.3$ & $0.5 \pm 0.3$ \\
\hline
\end{tabular}

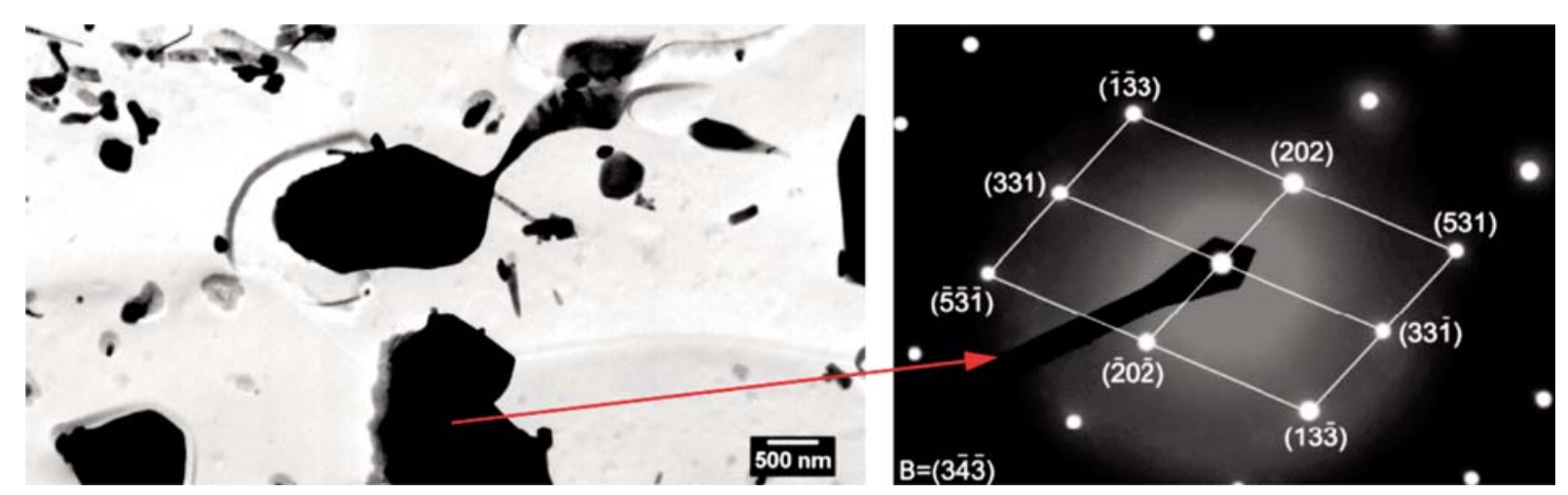

Fig. 4 Particle identified as M23C6 in the condition $750^{\circ} \mathrm{C} / 100 \mathrm{~h}$ (a), diffraction pattern corresponding to the marked particle (b), TEM of carbon extraction replicas

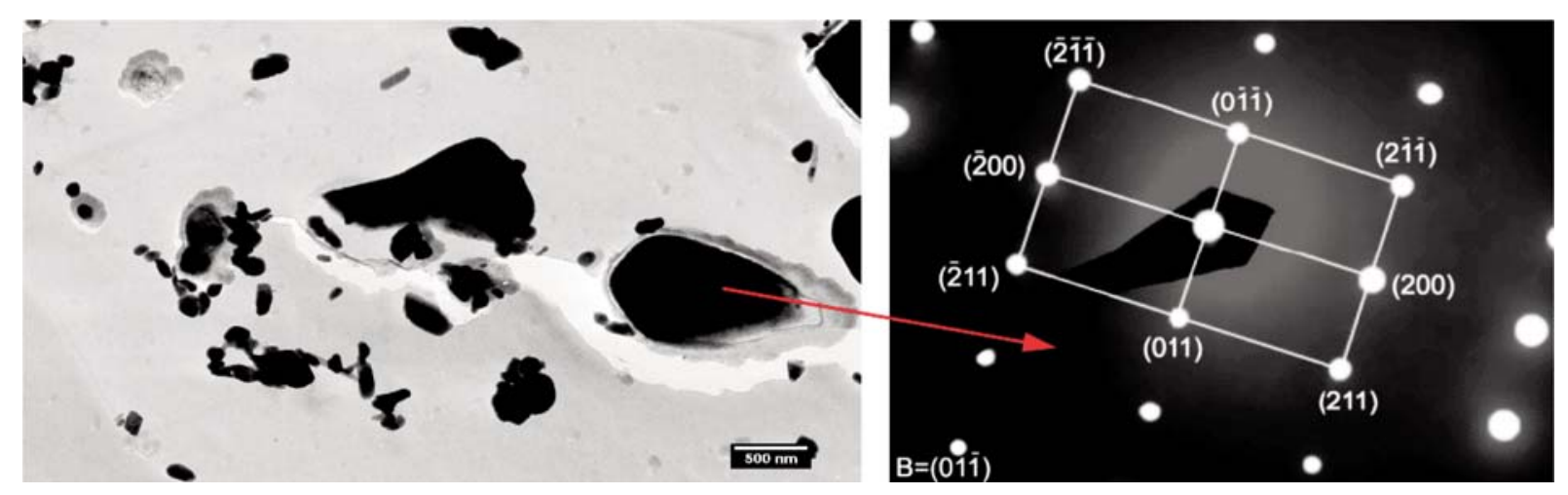

Fig. 5 Particle identified as chi in the condition $750^{\circ} \mathrm{C} / 100 \mathrm{~h}$ (a), diffraction pattern corresponding to the marked particle (b), TEM of carbon extraction replicas

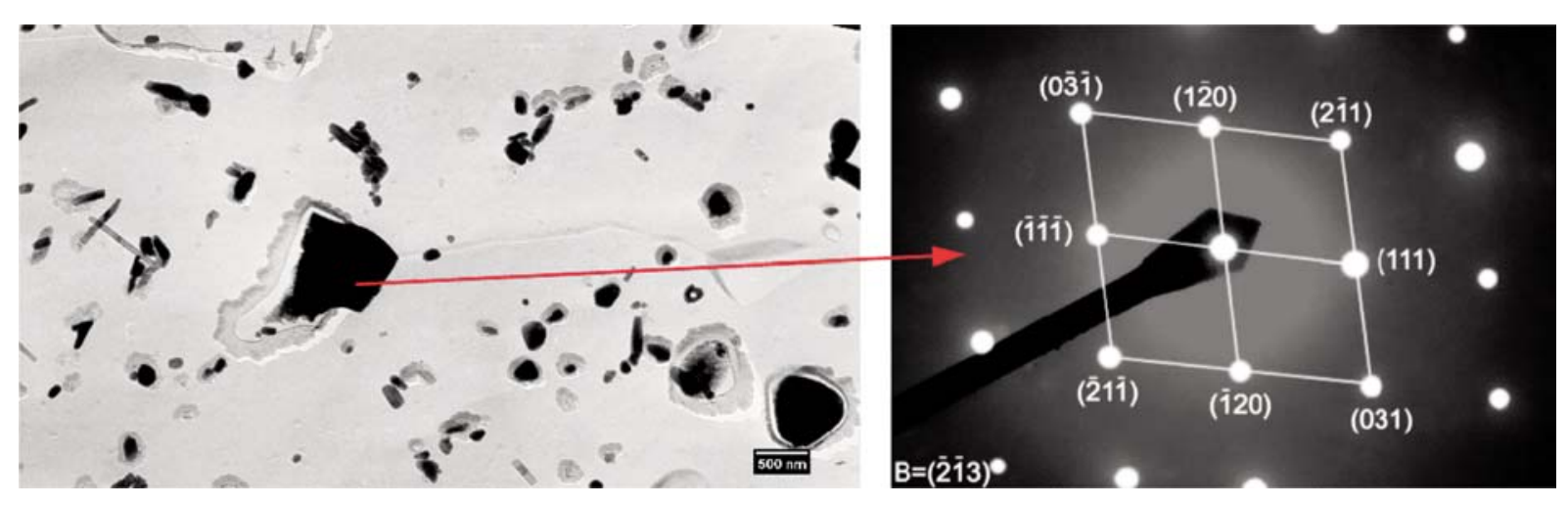

Fig. 6 Particle identified as sigma in the condition $750{ }^{\circ} \mathrm{C} / 100 \mathrm{~h}$ (a), diffraction pattern corresponding to the marked particle (b), TEM of carbon extraction replicas 


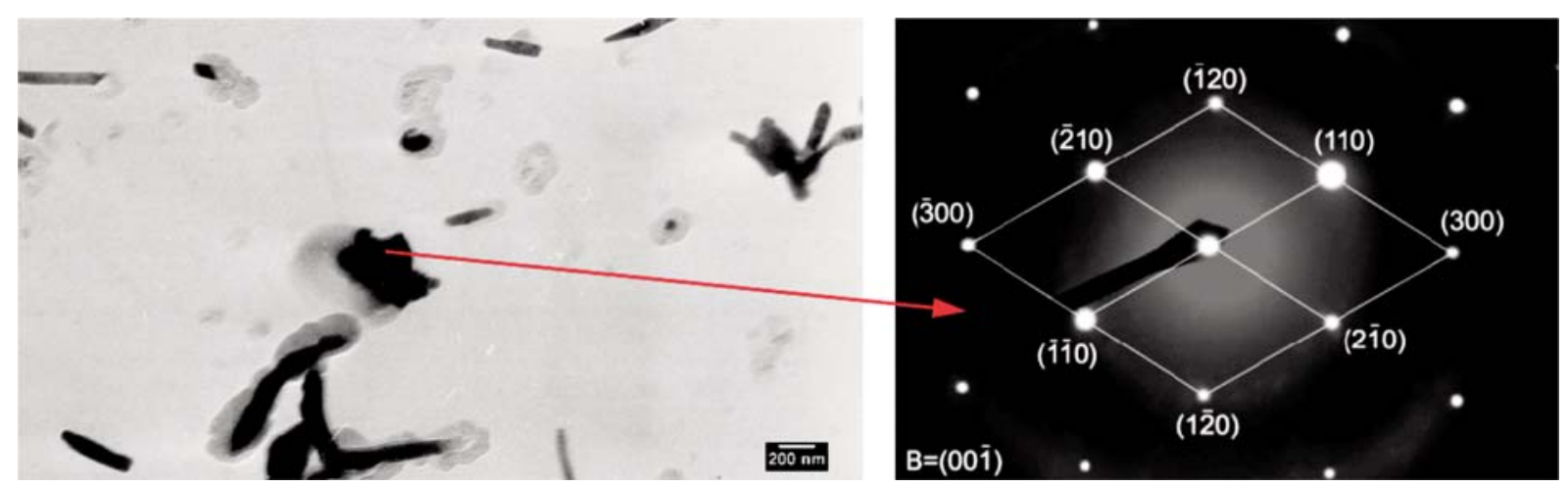

Fig. 7 Particle identified as laves in the condition $750^{\circ} \mathrm{C} / 100 \mathrm{~h}$ (a), diffraction pattern corresponding to the marked particle (b), TEM of carbon extraction replicas

The experimental characterization of secondary phases was done for the sensitised conditions only. The results of the thermodynamic calculations performed for the temperature range $500-1500{ }^{\circ} \mathrm{C}$ are shown in Table 4. According to the prediction, $\mathrm{M}_{23} \mathrm{C}_{6}$ is the only secondary phase in equilibrium with austenite at $750{ }^{\circ} \mathrm{C}$.

Phase equilibria predicted for the system corresponding Table 4 to the investigated AISI $316 \mathrm{~L}$ steel using ThermoCalc software

\begin{tabular}{|c|c|}
\hline $\begin{array}{c}\text { Temperature range } \\
{\left[{ }^{\circ} \mathrm{C}\right]}\end{array}$ & $\begin{array}{c}\text { Secondary phases predicted to be in } \\
\text { equilibrium with austenite }\end{array}$ \\
\hline $500-657$ & $\mathrm{M}_{23} \mathrm{C}_{6}+\mathrm{M}_{6} \mathrm{C}+$ sigma \\
\hline $658-744$ & $\mathrm{M}_{23} \mathrm{C}_{6}+$ sigma \\
\hline $745-849$ & $\mathrm{M}_{23} \mathrm{C}_{6}$ \\
\hline $850-1500$ & - \\
\hline
\end{tabular}

\section{Discussion}

Two important transitions between the analysed conditions of the AISI 316L steel were found as a result of the current study.

The transition between non-sensitised and sensitised states was determined between 1 and $2 \mathrm{~h}$ of annealing at $750{ }^{\circ} \mathrm{C}$ according to the corrosion test ASTM A 262, practice A (Fig. 2). During the annealing for $1 \mathrm{~h}$ (Fig. 3a) only small changes appear in the microstructure compared to the original $40 \% \mathrm{CW}$ condition (Fig. 1b). In spite of the "acicular" microstructures documented in Figs. $1 \mathrm{~b}$ and $3 \mathrm{a}$, the microstructure of the condition annealed for $2 \mathrm{~h}$ (Fig. 3b) contains also polyhedral grains surrounded with intergranular particles both features typical for recrystallization. Thus, it is probable that the sensitisation starts between 1 and $2 \mathrm{~h}$ of annealing due to a progress in the microstructure recovery and recrystallization.

The another important transition observed between 5 and $10 \mathrm{~h}$ of annealing concerns the number of identified secondary phases in the analysed conditions (Table 2). In general, the amount of secondary phase particles in the microstructure was found to increase with increasing the annealing time $[7,8,11]$. Sigma, laves and chi phases were identified in all conditions analysed. The precipitation of $\mathrm{M}_{23} \mathrm{C}_{6}$ started however between 5-10 h of annealing. This transition did not influence the steel resistance to intergranular corrosion (Fig. 2), because of a small amount of $\mathrm{M}_{23} \mathrm{C}_{6}$ particles in the low-carbon steel (Table 1) and the presence of chromium also in earlier precipitated intermetallic phases (Table 3).

Sigma, chi, and $\mathrm{M}_{23} \mathrm{C}_{6}$ were found to precipitate mainly along the grain boundaries. On the other hand, laves precipitated in the grain interior in the form of fine mostly longitudinal particles (Fig. 7). This is in agreement with findings of Padilha and Rios [11]. After $50 \mathrm{~h}$ of annealing laves was also found on the grain boundaries in the form of massive particles.

Thermodynamic predictions of phase equilibria for the system corresponding to the AISI $316 \mathrm{~L}$ steel showed partial agreement with the experimental results. According to the prediction, $\mathrm{M}_{23} \mathrm{C}_{6}$ is the only secondary phase co-existing with austenite in equilibrium at $750{ }^{\circ} \mathrm{C}$ (Table 4). It shows that sigma, chi, and laves identified experimentally are probably stable phases on annealing for shorter times. In the investigated steel the equilibrium at $750{ }^{\circ} \mathrm{C}$ is expected to be reached after annealing for times evidently exceeding $100 \mathrm{~h}$. Then, the amount of the equilibrium $\mathrm{M}_{23} \mathrm{C}_{6}$ should increase at the expense of the non-equilibrium intermetallic phases.

The annealing time was not found to influence significantly average values of the metal composition of identified phases. This made possible to calculate the average metal compositions for particular phases regardless of the condition (Table 3). The biggest standard deviations were determined for laves, because the analysed particles of this phase were of smallest dimensions.

\section{Conclusions}

In the present work the influence of secondary phase precipitation on the resistance to intergranular corrosion of the $40 \%$ cold work AISI $316 \mathrm{~L}$ steel annealed at $750{ }^{\circ} \mathrm{C}$ for $1,2,5,10,50$, and $100 \mathrm{~h}$ was investigated. Based on the experimental results the main findings can be summarized as follows: 
1. The transition between non-sensitised and sensitised states was found to be between 1 and $2 \mathrm{~h}$ of annealing.

2. Sigma, laves, and chi were identified in all the analyzed conditions although they were not predicted to be equilibrium phases at $750{ }^{\circ} \mathrm{C} . \mathrm{M}_{23} \mathrm{C}_{6}$, predicted to be in equilibrium with austenite at $750{ }^{\circ} \mathrm{C}$, started to precipitate between 5 and $10 \mathrm{~h}$ of annealing.

3. Particles of sigma, chi, and $\mathrm{M}_{23} \mathrm{C}_{6}$ were observed mainly along the grain boundaries. Laves formed fine mostly longitudinal particles in the grain interior. After $50 \mathrm{~h}$ of annealing this phase was also observed on the grain boundaries in the form of massive particles.

4. The annealing time was found to influence the average metal composition of the identified secondary phases slightly only.

\section{Acknowledgement}

The authors wish to thank to the Grant Agency of the Ministry of Education of the Slovak Republic and the Slovak Academy of Sciences (VEGA) for financial support under the contract No. $1 / 0126 / 08$.

\section{References}

[1] PARVATHAVARTHINI, N, DAYAL, R.K.: Influence of Chemical Composition, Prior Deformation and Prolonged Thermal Aging on the Sensitization Characteristics of Austenitic Stainless Steels, Journal of Nuclear Materials 305, 2002, pp. 209-219.

[2] PARVATHAVARTHINI, N, DAYAL, R.K, GNANAMOORTHY, J.B.: Influence of Prior Deformation on Sensitization of AISI Type 316LN Stainless Steel, Journal of Nuclear Materials 208, 1994, pp. 209-219.

[3] MAGULA, V, LIAO, J, IKEUCHI, K, KURODA, T, KIKUCHI, Y, MATSUDA, F. New Aspects of Sensitization Behaviour in Recent 316 Type Austenitic Stainless Steels, Trans. JWRI, Vol. 25, 1996, pp. 49-58.

[4] ZAHUMENSKY, P, TULEJA, S, ORSZAGOVA, J, JANOVEC, J, SILADIOVA, V.: Corrosion Resistance of 18Cr-12Ni-2,5Mo Steel Annealed at 500-1050 C, Corrosion Science 41, 1999, pp. 1305-1322.

[5] DOMANKOVA, M, MAREK P, MORAVCIK, R.: Effect of Annealing at $650^{\circ} \mathrm{C}$ on Precipitation in Chosen Austenitic Stainless Steels, Acta Metallurgica Slovaca, 13, 2007, pp. 52-60.

[6] MAREK, P, DOMANKOVA, M.: Influence of 40\% Deformation on Sensitisation Characteristic of 316 and 316L Austenitic Stainless Steels, Acta Metallurgica Slovaca, 13, 2007, 61-67.

[7] VACH, M., KUNIKOVA, T., DOMANKOVA, M., SVEC, P., CAPLOVIC, L., GOGOLA, P., JANOVEC J.: Evolution of Secondary Phases in Austenitic Stainless Steels During Long-term Exposures at 600, 650, and $800^{\circ} \mathrm{C}$, Materials Characterization 59, 2008, 1792-1798.

[8] WASNIK, D.N, DEY, G.K, KAIN, V, SAMAJDAR, I.: Precipitation Stages in a 316L Austenitic Stainless Steel, Scripta Materialia, 49, 2003, p. 135-141.

[9] AYDOGDU, G.H, AYDINOL, M.K.: Determination of Susceptibility to Intergranular Corrosion and Electrochemical Reactivation Behaviour of AISI 316L Type Stainless Steel, Corrosion Science 48, 2006, 3565-3583

[10] RAMIREZ, L.M, ALMANZA, E, MURR, L.E.: Effect of Uniaxial Deformation to 50\% on the Sensitization Process in 316 Stainless Steel, Materials Characterization 53, 2004, 79-82

[11] PADILHA, A.F, RIOS, P.R.: Decomposition of Austenite in Austenitic Stainless Steels, ISIJ International, Vol. 42, 2002, No. 4, pp. 330-332.

[12] ASM Handbook Vol. 13A Corrosion: Fundamentals, Testing and Protection. ASM International, 2003, pp. 266-267.

[13] LUKAS, H.L., FRIES, S.G., SUNDMAN, B.: Computational Thermodynamics. The Calphad Method. Cambridge University Press, 2007

[14] KROUPA, A.: Personal Communication. 